\title{
Assessment of Electricity Decarbonization Scenarios for New Zealand and Great Britain using a Plant Dispatch and Electrical Energy Storage Modelling Framework
}

\author{
Andrew Crossland ${ }^{1,2,3, *}$, Keith Scoles ${ }^{4}$, Allen Wang ${ }^{5}$, Chris Groves ${ }^{6}\left(\mathbb{D}\right.$ and Susan Sun ${ }^{7}$ \\ 1 Durham Energy Institute, Durham University, South Road, Durham DH1 3LE, UK \\ 2 Infratec, Level 13, Pencarrow House, 58-66 Jervois Quay, Wellington 6011, New Zealand \\ 3 Advance Further Energy Ltd, 14 Park Crescent, Retford, NOTTS DN22 6UF, UK \\ 4 Power it Fwd, 139 Morgans Road, Timaru, Canterbury 7910, New Zealand; keith.scoles@poweritfwd.co.nz \\ 5 FIndependent consultant, 54 Cobden Terrace, Gateshead NE8 3TB, UK; allenau84@gmail.com \\ 6 Department of Engineering, Durham University, South Road, Durham, DH1 3LE, UK; \\ chris.groves@durham.ac.uk \\ 7 Faculty of Engineering and Physical Sciences, University of Southampton, Southampton, SO17 1BJ, UK; \\ ss3g15@soton.ac.uk \\ * Correspondence: andrew@advancefurtherenergy.co.uk
}

Received: 24 April 2020; Accepted: 25 May 2020; Published: 1 June 2020

\begin{abstract}
This paper proposes a methodology to assess the impact of alternative electricity generation and energy storage scenarios for meeting electricity demand on a national level. The method combines real and synthetic electricity generation and demand data to investigate different decarbonization strategies using solar and wind generation and electrical energy storage. This method is applied to provide relevant case studies for two geographically similar electricity systems in New Zealand and Great Britain. Newly available solar and wind data sets at hourly resolution are used within this method for these systems to assess the potential contribution of these technologies and as such, to refresh understanding of the impact of these technologies on decarbonization strategies against historical and future demand patterns. Although wind, solar and storage technologies are found to reduce the carbon emissions in both electricity systems, a key result is quantifying the impact this has on traditional generation as a backup resource. In New Zealand an investment in wind and solar equivalent to less than $15 \%$ of the wind/solar capacity in Great Britain is found to (i) reduce fossil fuel use to less than $2 \%$ of annual electricity generation requirements in the data assessed and (ii) remove the need for continuous operation of fossil fuel plants. Further, it is shown that existing hydro storage potential could be used to create near complete decarbonization of New Zealand electricity
\end{abstract}

Keywords: energy transition; renewable energy potential; energy storage; plant dispatch; decarbonization; electricity

\section{Introduction}

The increasing urgency to mitigate climate change [1] has shone a spotlight on how countries will meet future energy needs in a decarbonized manner. In 2018, 87\% of primary energy around the world was derived from fossil fuels [2], the combustion of which emits greenhouse gases (GHGs). Analysis of decarbonization scenarios for all energy vectors is completed at all levels of the energy industry from policymakers through to technologists. In particular, energy policy analysis at a national and local level is important in providing direction and providing a vision for how energy systems may change. 
By assessing a country's energy needs on the one hand and its capacity for renewable and low-carbon energy supply on the other, one can explore different scenarios for decarbonization. This can compare factors such as their technical feasibility, economic costs, environmental effectiveness and side-effects. Some examples of such national energy budgeting tools include the UK's Department of Energy and Climate Change 2050 calculator [3], the Netherlands' Energy Transition Model [4] and OnSSET, which has been used in Ethiopia [5], amongst other regions. A limitation of some of these approaches is that they do not necessarily account for temporal variation in energy supply and demand, which occurs on annual, seasonal, daily and hourly timescales.

Models such as EnergyPLAN [6,7], GeneSys [8], DESSTinEE [9] and Renpass [10] overcome this drawback by modelling the dispatch of the available power generators to meet electrical demand, timestep by timestep across a full year. These have been used for applications such as assessing how to reduce curtailment of wind assets [11]. To assess alternative scenarios, generator capacities in a time-series model can either be set using external knowledge of the system context or can be treated as decision variables in an optimization problem. This approach is taken by models such as TIMES [12], OSeMOSYS [13], Oemof [14], Calliope [15] and Temoa [16], wherein the objective is to minimize costs or GHG emissions. In summary, time series models are vital for energy analysis, particularly in electricity systems where supply and demand have historically needed to be closely matched in the absence of electricity storage buffers. Indeed, effective energy storage modelling itself requires time series analysis to understand charge and discharge behavior.

Two examples of electricity systems with high decarbonization goals and where an updated temporal energy analysis is warranted are New Zealand and Great Britain. Both systems cover a similar geographic extent but with vastly different populations and different generation mixes (as outlined in the following case study). For example, in the case of the New Zealand, work has previously been conducted [17] to understand future decarbonization. It was concluded that $100 \%$ renewable energy was possible using wind, geothermal and bioenergy/hydro peaking plants. However, this excluded lifecycle carbon emissions calculations, solar generation data, explicit modelling of electrical energy storage and demand increases, all of which are important aspects in assessment of future energy systems. Further, solar was excluded due to the nascent state of development at the time of publication in 2010, which has since changed and further emphasizes the importance of new methods of analysis.

In Great Britain, historical wind and solar data are now available which permits new approaches to the study of the system. Specifically, this means considering low carbon generation and energy storage at national level and in a temporal model. Similarly, historical wind data and solar irradiance data is available for New Zealand. This, alongside the wide availability of sub-hourly grid electricity generation data for these systems permits a new approach to whole system energy modelling as well as contextualization in terms of carbon intensity and the use of dispatchable generation considering wind, solar.

This paper proposes a simple method to allow alternative wind, solar and energy storage scenarios to be assessed and compared for meeting demand with hourly or sub-hourly resolution. Using this method, we assess how solar, wind and energy storage can impact annual carbon abatement and demand growth in Great Britain and New Zealand. Further, we seek to quantify the annual generation requirement to meet energy demand when renewable generation is low and storage facilities are empty. In addition to country specific insights into possible future energy generation scenarios, this paper builds a framework which allows similar analyses to be performed in other regions of the globe.

\section{Method}

To assess the effect of alternative generation and energy storage technologies for meeting electricity demand and the changing carbon intensity on a national level, a method for assessing the electricity supply with different generation mixes and energy storage is presented in Figure 1. This determines the electricity mix on an hourly or sub-hourly resolution as required or as data resolution permits. The model uses a pre-defined hierarchical plant dispatch model (presented in a simplified form in 
Table 1) which reflects the technical constraints of various technologies in a particular market, as well as a simple dispatch strategy for low carbon operation. For the purposes of this paper and for high level assessments proposed here, these technical constraints are organized into "dispatch classes."

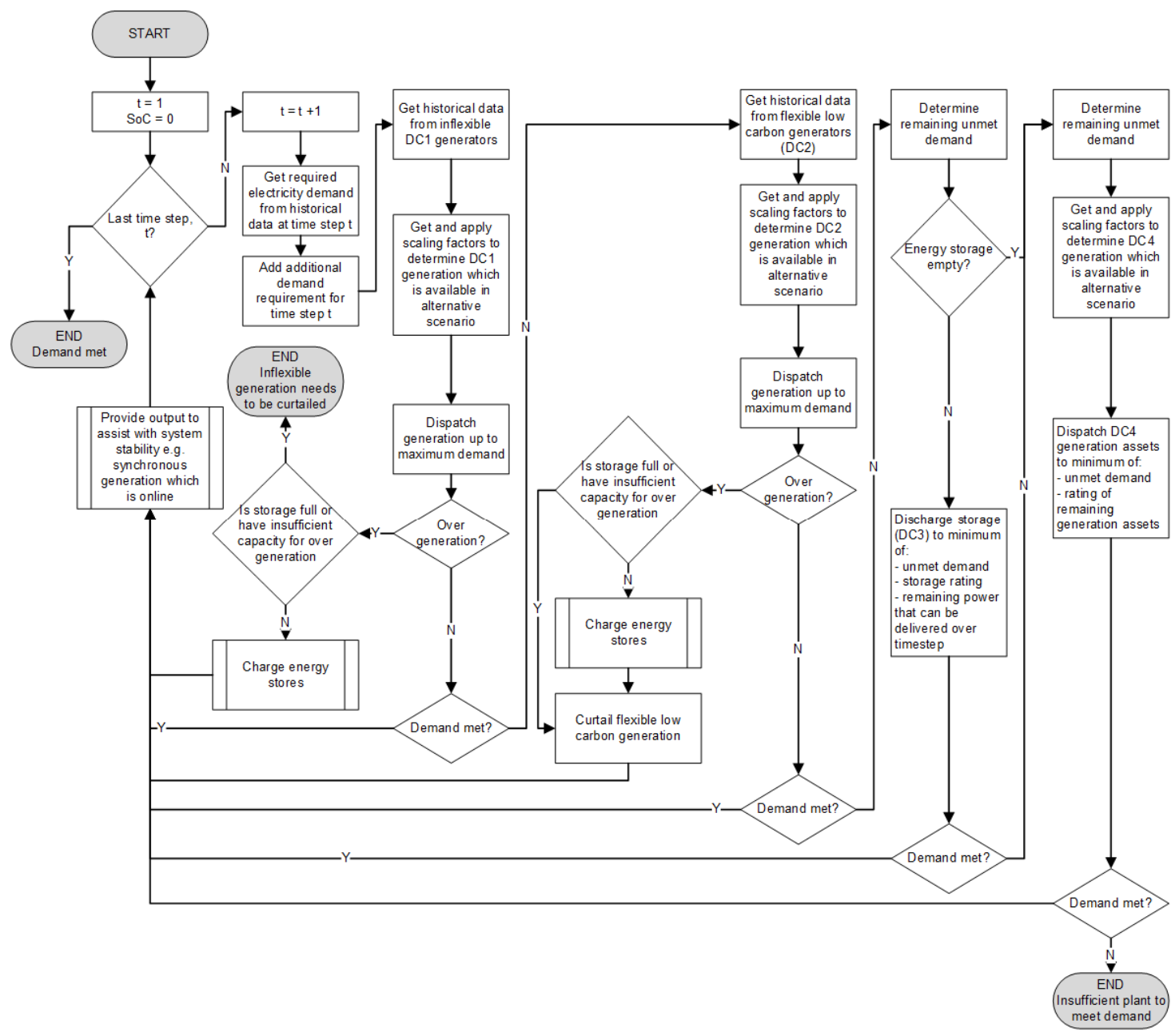

Figure 1. Plant dispatch model used in paper.

Inflexible plant is dispatched first (subject to historical availability) up to the required demand. Dispatch class 1 (DC1) assets are those such as nuclear and geothermal plants which run continually in the British and New Zealand markets, respectively, as well as distributed generation which cannot or should not be curtailed due to technical constraints (i.e., run of the river hydro generators which are not actively controlled).

If the demand is not met by inflexible plant, then more flexible low carbon generators (DC2) are dispatched to maximize their contribution to energy and decarbonization. The available generation is determined using historical generation data and simulations as described in Section 3. If DC1 and DC2 exceed demand, then energy storage charging can occur using overgeneration. If the storage is full, then DC2 assets are curtailed. If DC2 assets are insufficient to meet the demand of a particular time step, then DC3 assets are dispatched—this class includes energy storage assets as described in Section 2.1. If DC3 assets have exhausted their storage capacity or if they have insufficient capacity, then DC4 assets are dispatched. DC4 assets are low priority/last to dispatch assets such as peaking plant in a traditional market or potentially fossil fuels in a market with a high carbon price. These assets provide electricity to avoid brownout issues during shortages in electricity generation from DC1, DC2 and DC3. 
Table 1. List of generation types used in the plant dispatch model.

\begin{tabular}{|c|c|c|}
\hline Class & Class Description & Description \\
\hline DC1 & Inflexible Generation & $\begin{array}{l}\text { Generation types which must run continually i.e., } \\
\text { their historical dispatch cannot be changed e.g., } \\
\text { nuclear, non-dispatchable hydro plants, embedded } \\
\text { wind and solar generation etc. }\end{array}$ \\
\hline DC1hc & $\begin{array}{l}\text { High carbon generation with } \\
\text { dispatch restrictions }\end{array}$ & $\begin{array}{c}\text { Generation types which cannot generally } \\
\text { economically run for short periods and which are } \\
\text { high carbon e.g., coal }\end{array}$ \\
\hline DC2 & Flexible low carbon generation & $\begin{array}{l}\text { Low carbon generation types which can reduce their } \\
\text { output quickly or be curtailed as required by the } \\
\text { utility operator e.g., utility scale wind and solar }\end{array}$ \\
\hline DC3 & Energy Storage/Virtual Battery & $\begin{array}{l}\text { Energy storage facilities which can be used to provide } \\
\text { charging and discharging of energy such as batteries } \\
\text { and reservoir type hydro plants which can be used to } \\
\text { provide charging and discharging of energy. }\end{array}$ \\
\hline DC4 & Dispatchable plant & $\begin{array}{l}\text { Dispatchable generation which for technical, } \\
\text { economic or environmental reasons are dispatched } \\
\text { only when class 1-3 are insufficient to meet demand } \\
\text { such as gas power plants. This includes gas peaking } \\
\text { plants, flexible interconnectors or dispatchable } \\
\text { bioenergy generators. }\end{array}$ \\
\hline
\end{tabular}

In order to assess different energy scenarios for variable low carbon generation and plant availability, the model scales historical dispatch data (see Section 3 for the data used in this paper). This is completed using scaling factors which are designed to reflect alternative total installed capacity of different generation types. This is a simplistic approach which assumes spatial diversity within the existing dataset. To assess variations in demand, additional load is applied to the model using different load shapes as described in Section 4.3.

\subsection{Electrical Energy Storage}

Energy storage (DC3) assets are distinct from other generating assets since the model needs to reflect the fact that these can both increase generation requirements and provide energy to meet system demand. Storage is split into the following categories in this model:

1. Virtual storage (VS): storage permitted through deferring the use of a generating asset, such as hydropower where water is stored in a reservoir to be dispatched when there is insufficient generation from DC1 and DC2.

2. Reversible electrical energy storage (REES): assets such as batteries which charge from electricity, store it and then discharge electricity back into the electricity network.

For VS, energy stored during charge is the difference between the electricity dispatched during the historical data and that required in the model after other generation is dispatched. For hydrogenation, this reflects that water not dispatched for generation is instead kept within the hydro reservoir. This water may then be discharge for generation as per the dispatch strategy up to the maximum power capacity of hydro generation.

For REES, the capacity, charge/discharge rating and efficiencies are pre-defined. The storage is charged when the theoretical maximum generation of DC1 and DC2 assets exceeds total system demand. This is then discharged, after deducting efficiency losses, when the system is short on DC1 and DC2 generation. 


\subsection{Carbon Intensity Calculations}

Median lifecycle carbon intensity factors from the Intergovernmental Panel on Climate Change have been used (Table 2). These represent the lifecycle emissions of plants which are already committed (e.g., construction emissions of hydropower assets) as well as emissions in operation (e.g., combustion of fuels). As average values, these allow assessment of generic carbon savings in the absence of specific information on a plant by plant level. Within the model, the carbon intensity, $C_{t}$, of the electricity mix at time step $t$, is calculated as follows:

$$
C_{t}=\frac{\sum_{g=1}^{g} C_{g} \cdot E_{g, t}}{\sum_{g=1}^{G} E_{g, t}}
$$

where $C_{g}$ is the carbon intensity of generation asset $g$ at timestep $t$ and $E_{g, t}$ is the generation from asset $g$ at time $t$. This is extrapolated to determine long run carbon intensity, as required, in this model.

Table 2. Median carbon intensity of different electricity generating technologies-Median values from ref [18] unless otherwise stated.

\begin{tabular}{cc}
\hline Technology & Lifecycle Carbon Intensity $\left(\mathbf{g C O}_{\mathbf{2}} \mathbf{e q} . / \mathbf{k W h}\right)$ \\
\hline Coal & 820 \\
\hline Combined cycle gas & 490 \\
\hline Biomass co-fired with coal & 740 \\
\hline Dedicated Biomass ${ }^{*}[19]$ & 23 \\
\hline Nuclear & 12 \\
\hline Utility scale solar PV & 48 \\
\hline Rooftop solar PV & 41 \\
\hline Wind Offshore & 12 \\
\hline Wind Onshore & 11 \\
\hline Geothermal & 38 \\
\hline Hydropower & 24 \\
\hline Diesel [19] & 778 \\
\hline
\end{tabular}

* Note, as outlined in [20] this does not include $\mathrm{CO}_{2}$ absorption in growth and so alternative values are used

\section{Case Study}

Britain and New Zealand present an interesting comparative analysis for applying and testing the model. New Zealand is an interconnected twin island electricity system with a large baseload of hydropower generation which is supplemented with geothermal, fossil fuel (coal/gas) and wind generation. Britain also operates an island network but with some interconnection to continental neighbors. Despite having a comparable land area $\left(242,000 \mathrm{~km}^{2}\right)$ to New Zealand $\left(268,000 \mathrm{~km}^{2}\right)$, Britain has a much larger electricity demand and population density and over $70 \%$ of electricity is generated from nuclear, coal and gas. Conversely, New Zealand has over $80 \%$ of annual demand met by low marginal carbon generators. In this paper, the method is used to compare different decarbonizations routes for electricity scenarios in both countries. For the purposes of this paper, Britain refers to parts of England, Scotland and Wales served by the transmission system run by National Grid and New Zealand means North and South Islands. 


\subsection{British Electricity System}

British electricity demand was 274.9 TWh in 2017 and generation comprised a baseload of nuclear generation with wind, solar and hydro generally dispatched at maximum capacity within demand constraints. Gas, coal, biomass and imports (via interconnectors) are then dispatched in order to meet demand requirements. With respect to modelling (Table 3) inflexible nuclear generation, distributed solar PV combined with non-dispatchable hydropower are used to provide baseload electricity under the DC1 asset class. Most existing solar generation and some wind operates in the DC1 class due to the system operator not directly curtailing these. Large biomass plants are thermal/steam based plants with less flexible dispatch and are therefore also classed as DC1. Offshore wind and large wind farms also operated in the DC2 class, being curtailable by the system operator within the balancing system [21]. All existing and future grid solar generation is assumed to fall within this asset class if fitted with control mechanisms for curtailment and as required for stable operation of the grid. Energy storage assets, predominantly pumped hydro and battery storage plants, are considered to be DC3, whilst DC4 assets comprise biomass and then gas and coal—although it is worth noting that all British coal power stations are due to be decommissioned by 2025 [22]. Imports are also included as DC4 assets.

Table 3. Generation types in Britain and New Zealand as per the definitions in the method section. Note that coal is not included in British electricity in line with a policy to decommission all coal generation plants. The order of assets in each dispatch class shows the dispatch order within the class.

\begin{tabular}{ccc}
\hline Dispatch Class & Britain & New Zealand \\
\hline DC1 & $\begin{array}{c}\text { Nuclear, Behind the meter solar, } \\
\text { large biomass }\end{array}$ & $\begin{array}{c}\text { Geothermal, Behind the meter solar } \\
\text { Inflexible hydro e.g., micro hydro }\end{array}$ \\
\hline DC2 & Hydro, Utility scale solar, Wind & $\begin{array}{c}\text { Run of River Hydro, Wind, Utility } \\
\text { scale solar, hydro }\end{array}$ \\
\hline DC3 & Pumped hydro, Battery & Hydro reservoirs, Battery \\
\hline DC4 & Interconnector imports, Gas & Gas, diesel, coal \\
\hline
\end{tabular}

As of December 2017, Britain had 16.9 GW of wind and 12.1 GW of solar PV [23]. 9.68 GW of wind was registered in the balancing mechanism data used for this study as of December 2017 [24]. All solar PV generation data for Great Britain is provided from national PV output estimates from [25]. Within the model, the solar yield is $885 \mathrm{kWh} / \mathrm{kWp}$, in line with the input data and the wind capacity factor is $30.7 \%$, in line with the average capacity factor of onshore and offshore wind in the UK between 2017 and 2018 (25.7\% and 35.6\% respectively) [26]. For simplicity, a 50/50 split between onshore and offshore wind is assumed for modelling purposes although this may be adjusted to assess different policy scenarios. British solar PV data is available in the data used for other generation types described above.

\subsection{New Zealand Electricity System}

New Zealand had an annual generation of 42.9 TWh in 2017 with 39.4 TWh of electricity consumption which is down from a peak of 40.7 TWh in 2010 [27]. As of December 2017, the electricity system used a baseload of coal and geothermal generation supplemented by $326 \mathrm{MW}$ of wind and $72 \mathrm{MW}$ solar generation [28]. Hydro is dispatched as needed in order to meet demand and is supplemented by gas, bioenergy and diesel as required. Simplistically speaking, these are dispatched according to a locational marginal pricing auction.

To simulate a low carbon dispatch in the model, geothermal is considered to be a DC1 asset reflecting plant requirements. Wind, large solar and hydro are considered to be DC2 assets-assuming that the system operator can curtail electricity generation from these plants. DC3 energy storage is designated via the existing hydro storage plus energy storage. As of 2018, New Zealand has a nominal store of approximately $4 \mathrm{TWh}$ of storage in hydro lakes-although this is season dependent and 
includes storage reserved for periods of short supply [29]. Gas and diesel comprise DC4 plants. Within the model data, wind is found to have a capacity factor of $60 \%$ which is exceptional and a product of extremely high wind sites being selected in New Zealand for pilot projects. The wind capacity factor is therefore scaled back to $40 \%$ which represents a more realistic capacity factor based on evidence from New Zealand [30,31].

Hourly solar PV generation data have been derived using irradiance and temperature data over the study period in solar PV modelling software PVSyst [32]. The PVSyst profiles in New Zealand are weighted towards population by different regions to give an average pre-curtailment yield of $1,454 \mathrm{kWh} / \mathrm{kWp}$. This correlates with electricity generation yield from other sources [33].

\subsection{Classification of Generation and Storage}

The model requires hourly resolution data of the historical electricity generation mix. Historical electricity generation data for New Zealand has been sourced from Electricity Authority datasets [34]. Data for the British electricity generation mix has been sourced via the Balance Mechanism Reporting Service [24] and Sheffield University [25] to provide hourly dispatch of all major plant types in Britain. The study period is 2017, due to the availability of good quality data from this period. A summary of the generation types in New Zealand and Great Britain according to the categories defined in the method is provided in Table 3.

\section{Experimental Cases}

The model is run with a finite number of cases which are designed to quantify and assess changes to the generation mix and subsequent decarbonization.

- For New Zealand, wind and solar generation are incremented in 2 GW of capacity to 8 GW of wind and $6 \mathrm{GW}$ of solar respectively. Since solar generation is nationally reported on an hourly level, the existing solar generation is assumed to be demand reduction that is, is not visible in the data.

- For Great Britain, wind and solar generation is increased in increments of 7.5 GW. This higher value is chosen due to the larger generation in this electricity system.

These are selected to provide a range of scenarios from present volumes of renewable energy through to a scenario where the theoretical maximum output of DC1 assets plus wind and solar generation exceed peak electricity demand.

Whilst the analysis and model has focused on the issues surrounding energy balancing, the impact of issues such as market mechanisms, energy and networks constraints and the dynamic effects of changing grid inertia and so forth have not been addressed in this paper. This is a deliberate choice, as the model is to assess the pure energy feasibility of different electricity mix scenarios and it is anticipated that similar modelling can be undertaken to assess whether technology propositions can help achieve carbon targets or fossil fuel abatement.

\section{Results}

\subsection{Model Application}

In order to demonstrate the application of the model for subsequent result interpretation, a single analysis is performed on both New Zealand and Great Britain electricity systems and assessed in some detail. This is completed using a sample of summer data for Great Britain and winter data for New Zealand to show the model in opposite seasons.

\subsubsection{New Zealand}

An investigation of the New Zealand electricity mix using fourteen days of generation from August 2017 (which is typical of the annual electricity supply) is now described. In the counterfactual 
case shown in Figure 2a, there is a modest amount of baseload geothermal power supplemented by unconstrained wind generation, hydropower, gas and high carbon plant to meet demand. A two week analysis is shown in Figure 2b. Here, $2 \mathrm{GW}$ of wind and solar generators are added. This particular scenario is shown to abate all fossil fuel generation on four of the days and total fossil fuel use is reduced by more than $80 \%$ compared to the counterfactual. In Section 4.3 , this analysis is repeated with various wind/solar generation scenarios to investigate impacts these can have on carbon generation and fossil fuel use.

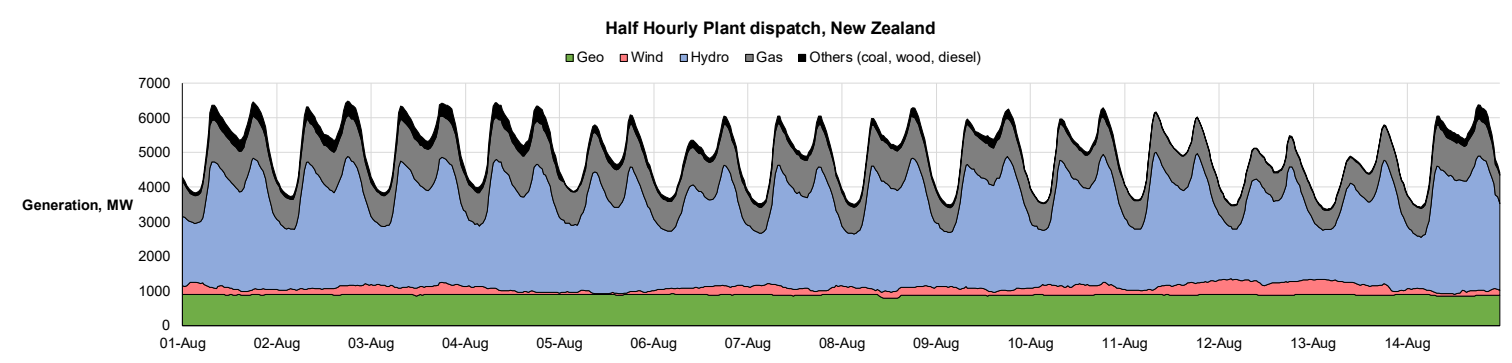

(a)

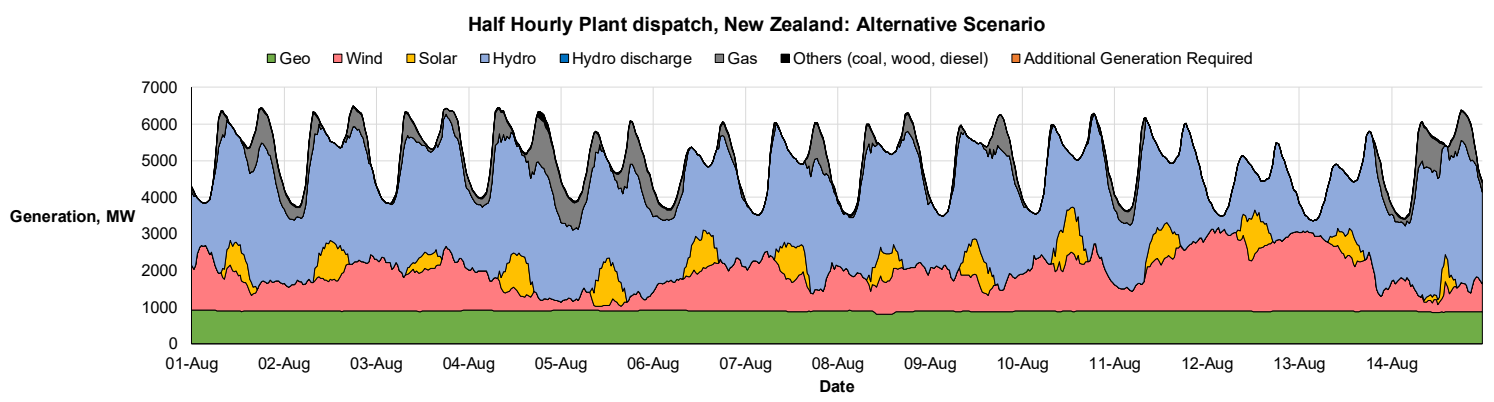

(b)

Figure 2. (a) Historical and (b) modelled electricity mix in New Zealand 1-7 August 2017 through application of the method proposed in this paper. Generation is in order of dispatch class. The model includes 2.0 GW of wind capacity and a $2.0 \mathrm{GW}$ solar PV.

The same scenario is next applied over the full annual dataset. The annual electricity mix and carbon emissions are shown in Figure $3 \mathrm{a}$ and $\mathrm{b}$ respectively. Figure 3a shows that the wind and solar generation reduce fossil fuel use to less than $2 \%$ of electricity generation over the year. Here, the majority of greenhouse gas emissions were still attributable to coal and gas (Figure 3b), despite these providing less than $17 \%$ of annual electricity. In the alternative scenario coal and gas are not completely eliminated due to insufficient stored hydro, wind or solar to meet demand at certain times (as shown in Figure 2b). However, the consequence of reducing fossil fuel use lowers overall emissions by $69 \%$ with the simulated growth in renewable generation. The reduced annual hydroelectricity generation requirement in the alternative scenario also means that the system is less exposed to lower reservoir levels in dry years such as that which occurred in 2017/18 [35] by keeping water in the hydroelectric reservoirs. The impact this has on utilization of fossil fuels is explored in Section 4.5.2

\subsubsection{Great Britain}

The method is then applied to data from the British electricity system. Figure 4a shows the British electricity mix for fourteen days in August 2017. A baseload of nuclear generation is supplemented by wind, solar, biomass and imports. Gas provides the most of supply and contributes most of the carbon emissions since coal is removed from the simulation (Figure $5 b$ ) - in line with UK targets. In the alternative scenario shown in Figure 4b, wind and solar have some days of oversupply followed by 
days where there is high gas use as a result of low wind/solar generation. Over the year, the alternative scenario shows carbon emissions reduced by $27.7 \%$.

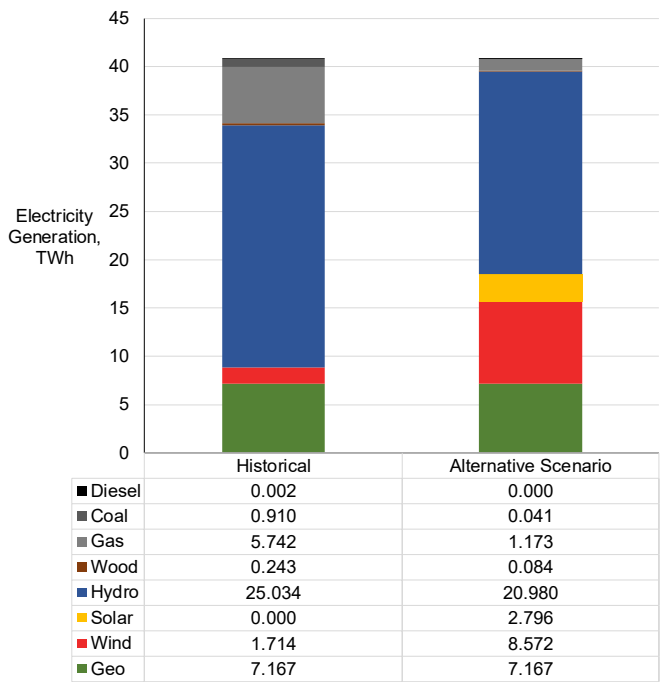

(a)

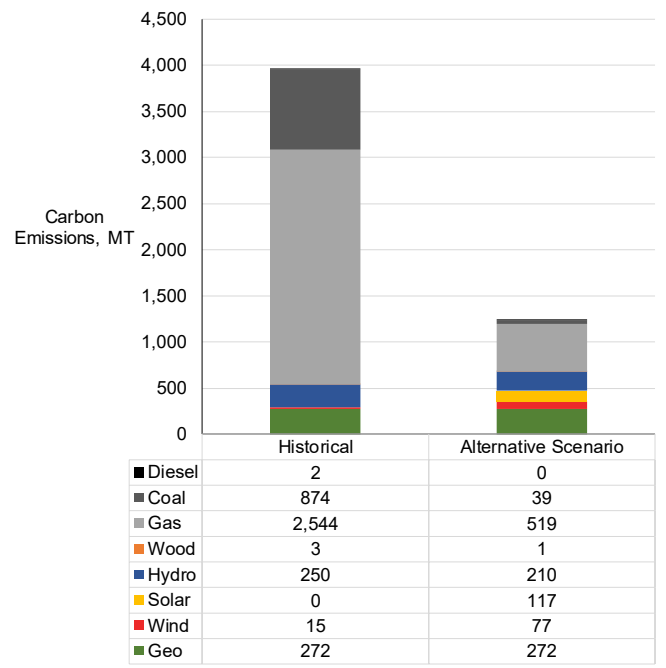

(b)

Figure 3. (a) Annual historical and alternative electricity mix in New Zealand and (b) projected carbon emissions from electricity generation with an additional $2.0 \mathrm{GW}$ of wind and solar PV.

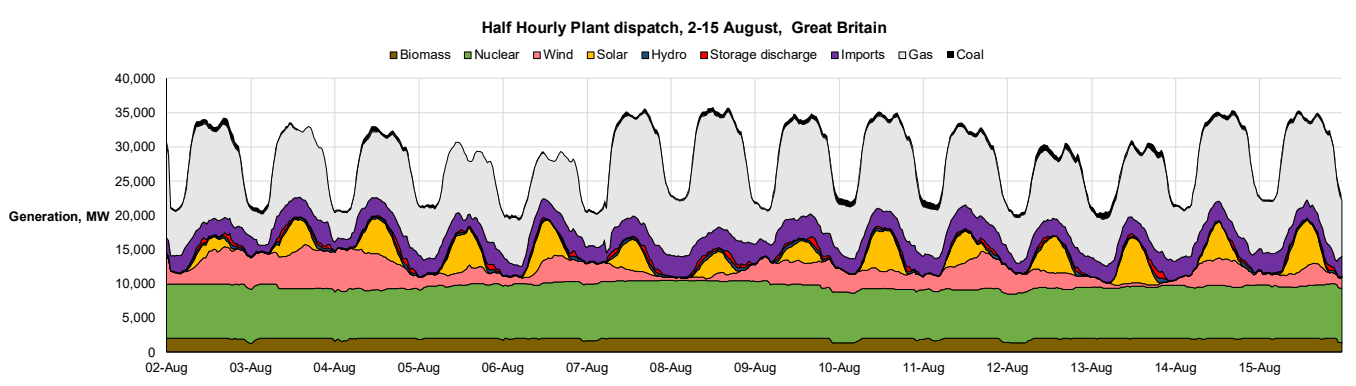

(a)

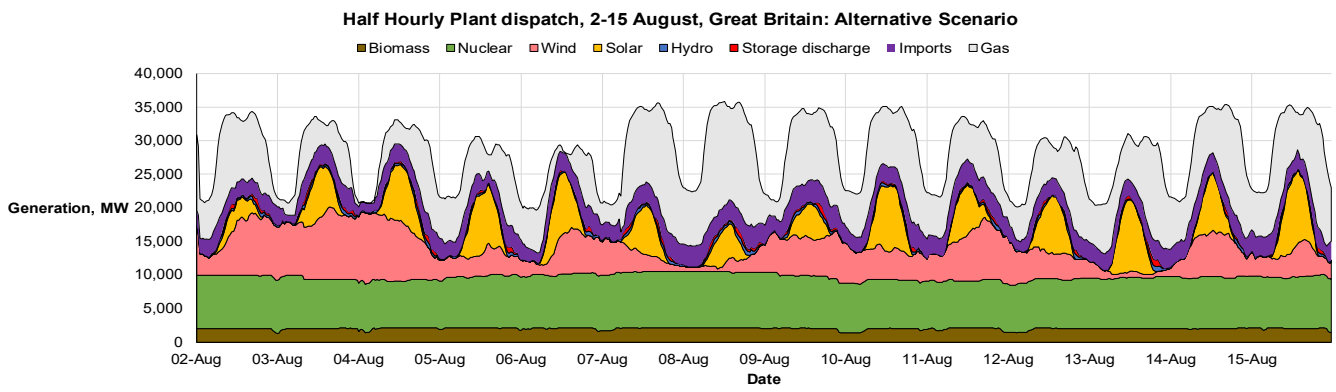

(b)

Figure 4. (a) Historical and (b) alternative electricity mix in Great Britain 2-16 August 2017 through application of the method proposed in this paper. Generation is in order of dispatch class. The alternative scenario represents a scenario $7.5 \mathrm{GW}$ of additional wind and solar PV.

\subsection{Impact of Wind and Solar}

The model is now applied to investigate how wind and solar can impact decarbonization and DC4 utilization over a range of scenarios. Table 4 shows the carbon intensity of and percentage of supply from fossil fuels in New Zealand with the 2017 electricity mix $(97 \mathrm{gCO} 2 \mathrm{eq} . / \mathrm{kWh}, 16.3 \%$ fossil 
fuel generation) and with the addition of solar and wind generation installed in a 12-month alternative scenario. The higher capacity factor of wind generation means that lower carbon intensities and higher fossil fuel abatement per $\mathrm{kW}$ of wind installed are achieved. However, the abatement of fossil fuels and reduction in carbon intensity is highest through a strategy of employing both wind and solar generation. There is a limit on the amount of fossil fuel abatement; there are always some days with insufficient wind or solar generation where a dispatchable source must be used. The results suggest that the installation of wind and solar should be controlled to balance marginal gains in carbon reduction, costs of electricity and investment economics. Further, it is worth considering if the annual energy requirements from DC4 assets can be met from low carbon sources such as bioenergy.

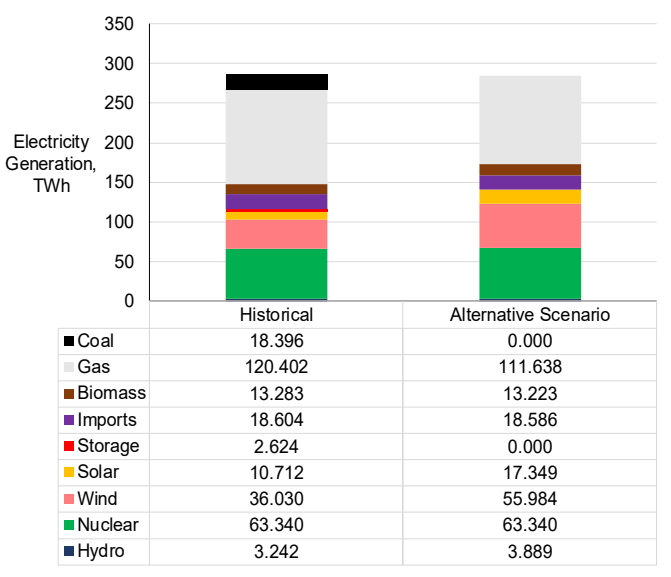

(a)

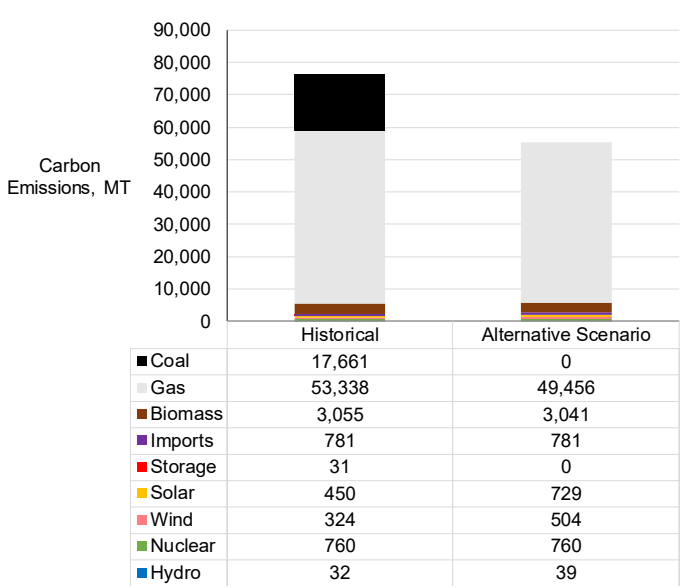

(b)

Figure 5. (a) Annual historical and alternative electricity mix in Great Britain and (b) projected carbon emissions from electricity generation with 7.5 GW of additional wind and solar PV.

Table 4. Carbon intensity of New Zealand electricity under different PV and wind scenarios ( $\mathrm{gCO}_{2}$ eq./kWh) and (percentage of electricity supplied by DC4 assets). Note that the embedded carbon in solar generation causes a rise in carbon intensity after a certain deployment due to overgeneration effects.

\begin{tabular}{lccccc}
\hline & & \multicolumn{4}{c}{ Additional Solar, GW } \\
\cline { 2 - 6 } & & $\mathbf{0 . 0}$ & $\mathbf{2 . 0}$ & $\mathbf{4 . 0}$ & $\mathbf{6 . 0}$ \\
\hline \multirow{3}{*}{$\begin{array}{c}\text { Additional } \\
\text { Wind, GW }\end{array}$} & 0.0 & $97(16.3 \%)$ & $69(10.7 \%)$ & $65(9.3 \%)$ & $66(8.9 \%)$ \\
\cline { 2 - 5 } & 2.0 & $38(5.0 \%)$ & $30(2.9 \%)$ & $31(2.6 \%)$ & $32(2.5 \%)$ \\
\cline { 2 - 5 } & 4.0 & $26(2.4 \%)$ & $23(1.4 \%)$ & $24(1.2 \%)$ & $25(1.2 \%)$ \\
\cline { 2 - 6 } & 6.0 & $22(1.6 \%)$ & $20(0.9 \%)$ & $21(0.8 \%)$ & $21(0.7 \%)$ \\
\cline { 2 - 6 } & 8.0 & $20(1.2 \%)$ & $19(0.7 \%)$ & $19(0.6 \%)$ & $20(0.6 \%)$ \\
\hline
\end{tabular}

Table 5 shows a sensitivity analysis of increased wind/solar generation in Great Britain with associated reduction in carbon intensity and utilization of DC4 assets. As shown, the increase in variable generation reduces carbon and DC4 utilization but the reduction is subject to a diminishing return. Wind has a greater impact on carbon saving, due to the greater yield per unit of wind installed.

Figure 6 summarizes the diminishing impact of wind and solar on the use of fossil fuel generation under various scenarios. This shows that it is difficult to provide $100 \%$ low carbon electricity with wind and solar alone. Reflecting on Figures 3 and 4 in can be seen that wind and solar capacity in the limited geographic spread of the UK and New Zealand still leaves times at night or on cloudy days where solar output is too low or still days across the country when wind output is low. This suggests that variation in wind and solar supply through greater geographic spread around the country could reduce 
the severity of local "peaks" and "troughs" in output. However, there will always be national level decreases in output where DC3 (storage) and DC4 assets are required to be dispatched. The utilization of DC3 and DC4 assets is explored in Section 4.4.

Table 5. Carbon intensity of British electricity under different PV and wind scenarios ( $\mathrm{gCO}_{2} \mathrm{eq} . / \mathrm{kWh}$ ) and (percentage of annual electricity supplied by fossil fuel based DC4 assets).

\begin{tabular}{ccccccc}
\hline & & \multicolumn{5}{c}{ Additional Solar PV Over 2017 Installed Capacity, GW } \\
\cline { 2 - 6 } & & $\mathbf{0 . 0}$ & $\mathbf{7 . 5}$ & $\mathbf{1 5 . 0}$ & $\mathbf{2 2 . 5}$ & $\mathbf{3 0 . 0}$ \\
\hline \multirow{2}{*}{$\begin{array}{c}\text { Additional wind } \\
\text { over 2017 } \\
\begin{array}{c}\text { installed } \\
\text { capacity, GW }\end{array}\end{array}$} & 0.0 & $232(48.2 \%)$ & $223(45.9 \%)$ & $214(43.6 \%)$ & $205(41.5 \%)$ & $198(39.7 \%)$ \\
\cline { 2 - 6 } & 7.5 & $202(41.2 \%)$ & $193(38.9 \%)$ & $184(36.7 \%)$ & $176(34.8 \%)$ & $169(33.2 \%)$ \\
\cline { 2 - 6 } & 15.0 & $174(34.8 \%)$ & $165(32.6 \%)$ & $157(30.6 \%)$ & $149(28.8 \%)$ & $143(27.4 \%)$ \\
\hline
\end{tabular}

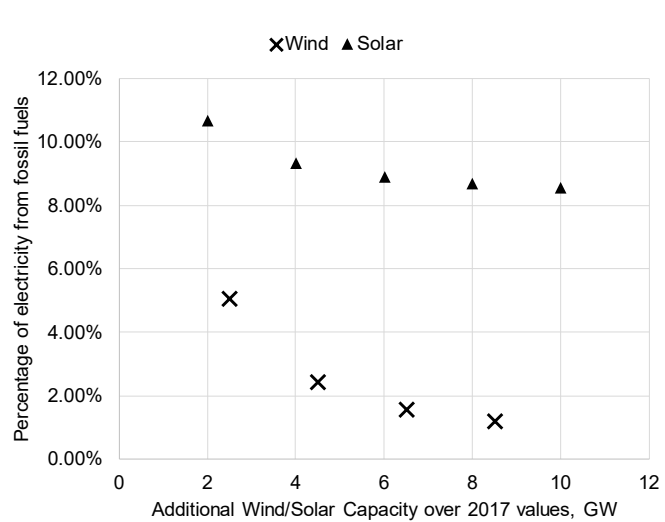

(a)

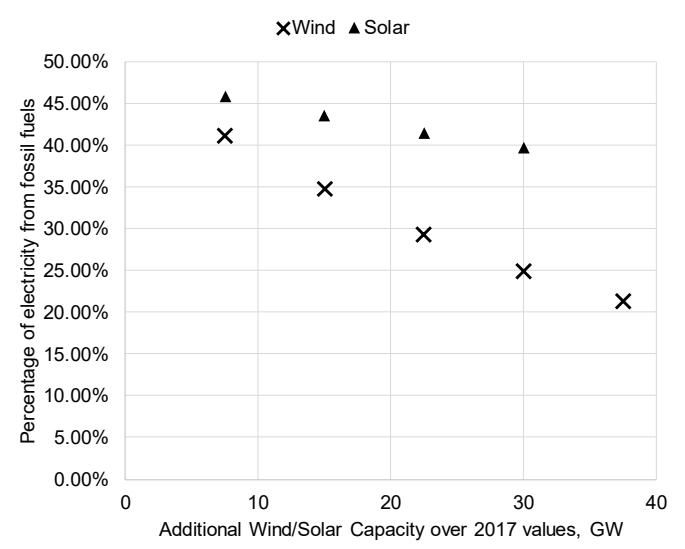

(b)

Figure 6. Annual energy requirements from DC4 assets under increasing wind and solar penetration-Applied to (a) New Zealand and (b) Great Britain (fossil fuel based only).

\subsection{Demand Growth}

Increased electrical consumption is anticipated in Great Britain and New Zealand through a combination of factors such as economic growth and electrification of heat and transport sectors. For example, the New Zealand system operator expects electricity demand to increase from $\approx 40 \mathrm{TWh}$ in 2017 to $\approx 90 \mathrm{TWh}$ in 2050 [36] under one scenario. In Great Britain, annual electricity demand increases from $\approx 300$ TWh to $\approx 412-475$ TWh from 2018 to 2050 under various scenarios [37]. The model is therefore extended to include load growth scenarios to determine the impacts on the electricity mix.

For New Zealand, load growth scenarios based on "scenario Waka" in [38] is examined. This projects electricity generation will grow to 48 TWh by 2030 and 59.6 TWh by 2050 . There are numerous uncertainties to the shape of future load curve such as peak load impacts investigated in [9] and impacts of smart charging and tariffs. For simplicity in this model, load growths are applied to the demand requirements as daytime loads ( 6 am to 6 pm), noted as 'day' in Figure 7 and 24-h loads, noted as 'flat' in Figure 7.

The impact of demand growth on generation requirements is shown in Figure 7. In (a) it is found that the use of DC4 assets is less than 4 TWh in the most aggressive wind/solar case. This compares to a total generation from coal and gas in New Zealand of 6.6 TWh in 2017. In (b) the increased carbon intensity as a result of increased demand is found to fall below 2017 levels with the highest wind and solar generation scenarios. 


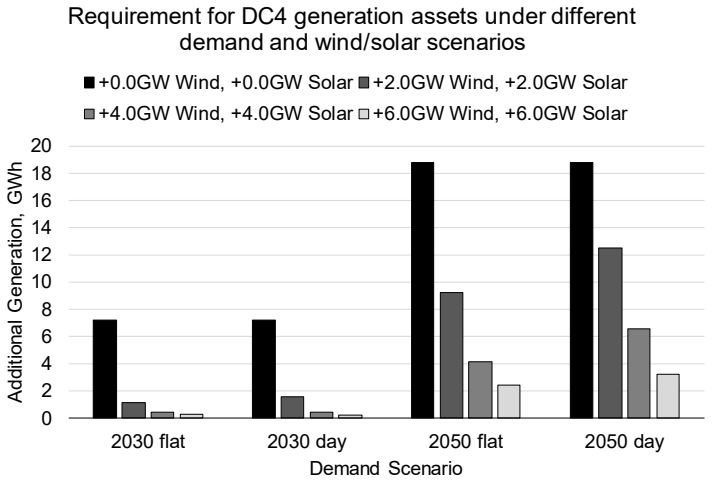

(a)

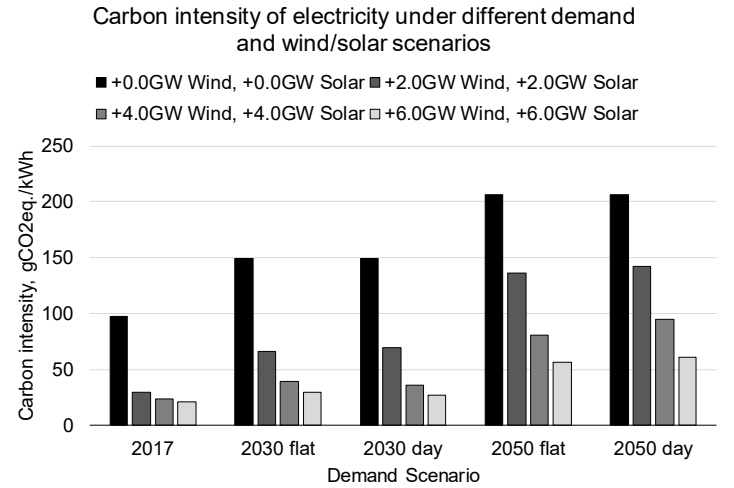

(b)

Figure 7. (a) Requirements for DC4 assets and (b) carbon intensity under different demand scenarios in New Zealand. Note that additional generation required to meet demand is assumed to be gas generation as the lowest carbon fossil fuel based DC4 asset.

\subsection{DC4 Impact Factors}

Figure 8 shows the impact that wind or solar generation installed in New Zealand and Great Britain have in reduction of DC4 utilization before demand growth. As opposed to capacity, the charts show the impact relative to energy (TWh) produced. The impact of both wind and solar decreases rapidly in New Zealand as penetration approaches 100\%. In Great Britain, solar and wind are found to have a declining but not asymptotic reduction in DC4 usage in the range considered. The results indicate an immediate impact of wind and solar in New Zealand will be larger than in Great Britain in percentage terms-despite New Zealand having a more decarbonized electricity mix in the counterfactual case.

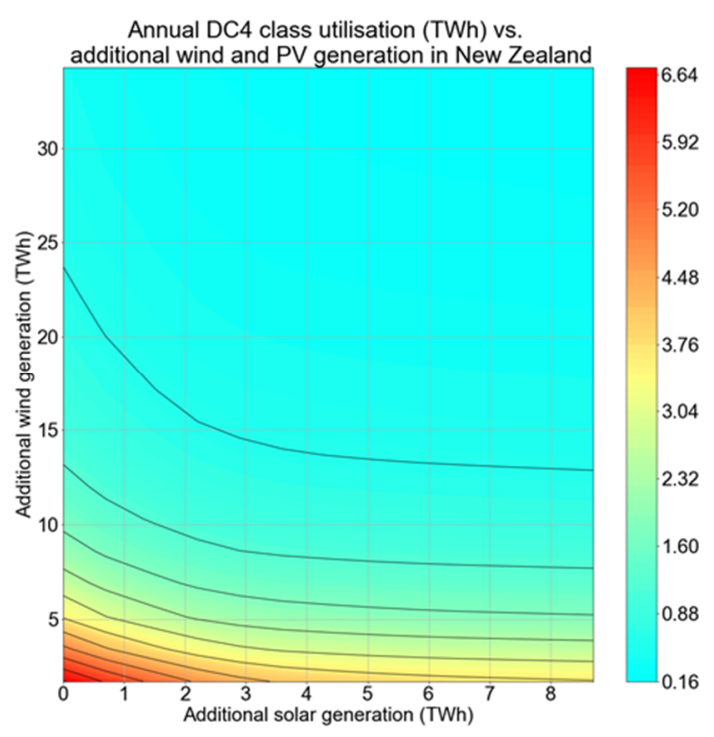

(a)

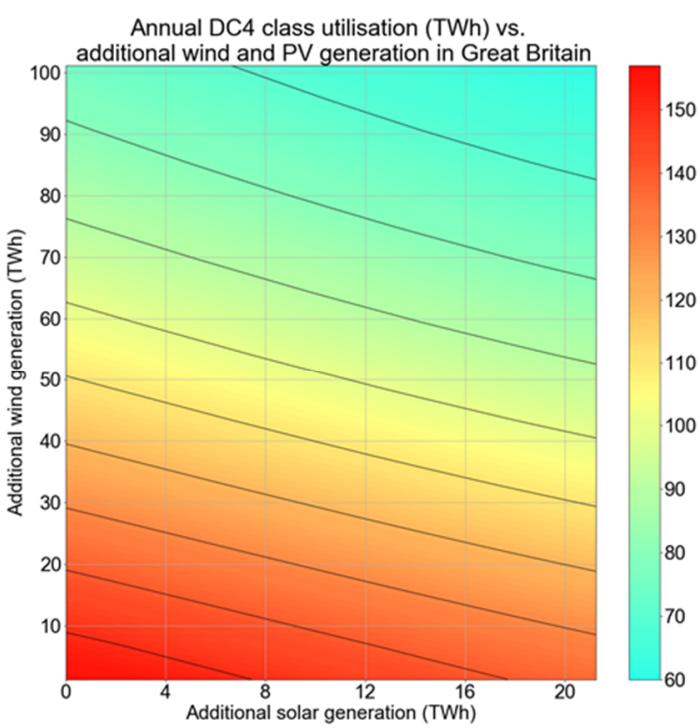

(b)

Figure 8. Annual generation from DC4 assets in (a) New Zealand and (b) Great Britain under different solar and wind generation scenarios-denoted by the maximum theoretical pre-curtailment generation of each technology in TWh per year.

The reasons for this are shown in Figure 9 which shows that the wind data from Great Britain has lower capacity factors and a more seasonal profile meaning that it is less likely to be able to meet demand than New Zealand wind which is found to have a higher and more consistent capacity factor. 
This finding supports higher capacity wind that provide electricity more consistently over the-such as offshore wind installations.

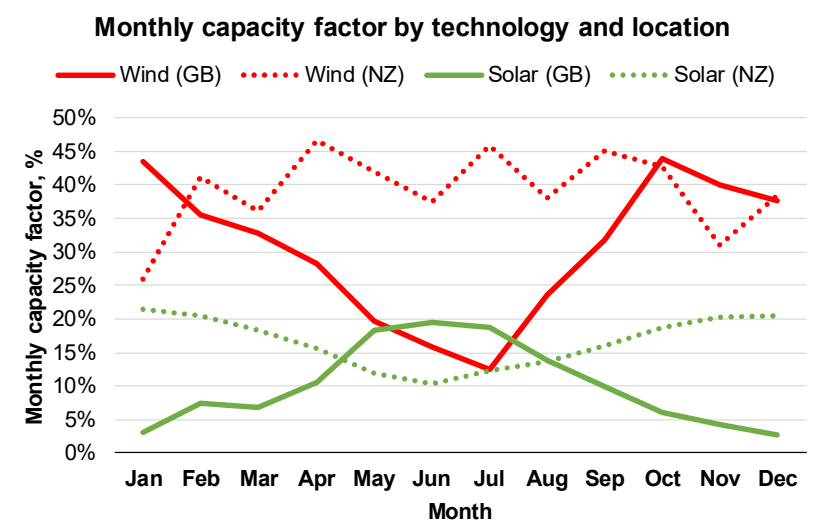

Figure 9. Capacity factor of wind and solar generation as modelled for New Zealand and Great Britain. Trends mirrored in (Ministry of Business, Innovation and Employment, 2019) (Ministry of Business, Innovation and Employment, 2019).

\subsection{Operating Considerations}

\subsubsection{DC3/Energy Storage Impact}

A sensitivity analysis of the impact of energy storage on fossil fuel abatement in shown in Figure 10 for various solar and wind integration scenarios. Here, storage is charged from DC2 assets which would otherwise need to be managed (e.g., curtailed) when the supply exceeds demand and the storage is discharged when supply from DC1 and DC2 assets are insufficient to meet demand.

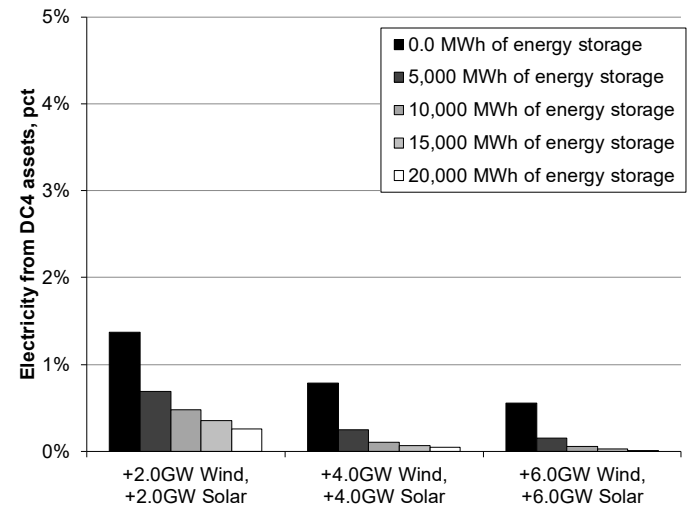

(a)

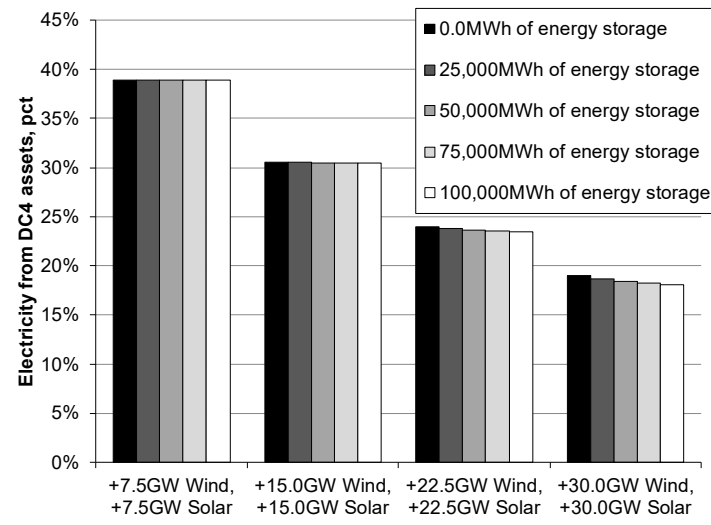

(b)

Figure 10. Annual percentage of electricity from DC4 assets under different energy storage scenarios in (a) New Zealand and (b) Great Britain.

In New Zealand, energy storage is found to have limited impact on fossil fuel abatement from an energy balancing perspective until the installed capacity of wind and solar increases beyond 1.5 GW. This is because there is little excess generation from wind or solar until this scenario. From this point, increasing the amount of DC2 generation gives sufficient over-generation for charging the storage. In the $+2 \mathrm{GW}$ Wind/+4 GW solar scenario (high DC2 penetration), a modest amount of flexibility, $5000 \mathrm{MWh}$ is sufficient to reduce fossil fuel use by around 50\%-although from a very low base.

In Britain, new energy storage capacity would practically have to come from investment in new assets. However, in New Zealand it is worth noting that as of 2018, the total hydro storage is considered 
to be 4042 GWh divided between contingent and controlled storage [39]. Although there is limited ability at present to pump water in the dams by means of storage, this study shows that doing so could result in near complete DC4 reduction in the high DC2 cases-based on 2017 demand data. Further, the DC4 utilization in this case is of a comparable magnitude to the bioenergy used in New Zealand in 2017 (Figure 2a) which suggests that decarbonization of the DC4 asset class may be worth considering by policymakers.

It is noted that the DC3 impact on DC4 utilization is more significant in New Zealand than in the UK. The highest storage scenario considered for New Zealand would meet average annual electricity demand $(4.7 \mathrm{GW})$ for $4.3 \mathrm{~h}$ relative to the storage in Great Britain meeting average demand $(32 \mathrm{GW})$ for $2.4 \mathrm{~h}$. This is likely due to the more consistent capacity factor of wind generation in New Zealand (Figure 9).

\subsubsection{DC4 Utilization}

Figure 11 shows the dispatch behavior of DC4 assets under increased penetration of wind and solar generation. In the base case, DC4 assets provide around $500 \mathrm{MW}$ of power almost continually. There is a reducing amount of time when the assets provide a large amount of power-such as peaking loads or during outages of other plants. As the increase of wind and solar capacity changes the dispatch of DC4 plants, these increasingly become utilized for intermittent rather than continuous operation. This is due to wind, solar and other assets covering the DC4 requirements by approximately $65 \%$ of the year. These charts show that increased investment in wind and solar reduces the need for DC 4 assets from a volumetric/energy perspective although the power requirement remains consistent. This shows that providing DC4 capacity requires new operating models, such as plants designed for economic dispatch with infrequent operation for example, gas peakers.

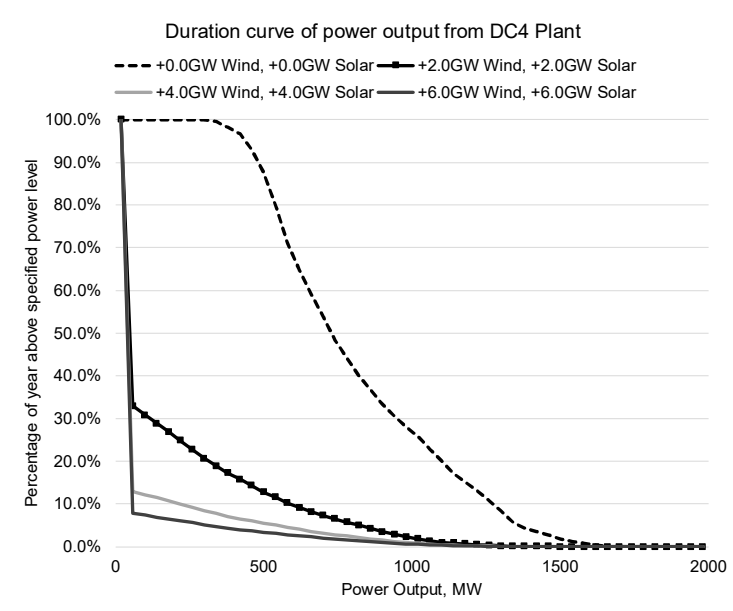

(a)

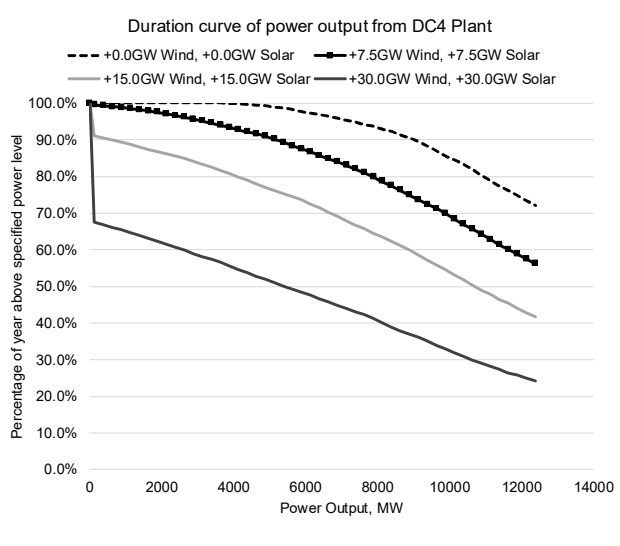

(b)

Figure 11. Histogram of dispatch times of DC4 assets different generation alternative scenarios in (a) New Zealand and (b) Great Britain.

\section{Discussion}

This paper has presented a simple method for assessment of integration of further wind and solar within electricity grids by classification and scaling of different generation assets. This has been applied to assess electricity supply in New Zealand and Great Britain.

The results show wind and solar investment can have a significant impact towards decarbonization of both electricity systems, despite inherent variability of both generation sources. In New Zealand, a modest wind and solar growth could mean that $99 \%$ of present electricity demands can be met from low marginal carbon/renewable sources with consequent reduction in greenhouse gas emissions. The results show, for New Zealand, $+2.0 \mathrm{GW}$ of wind and 2.0 GW of solar reduce DC4 assets to less 
than $2 \%$ of supply which contrasts with the work of [17] which used additional geothermal generation and a similar amount of wind to achieve a similar result. To consider how small an increase in low carbon generation this is, it is equivalent to $15.9 \%$ of the solar and $13.6 \%$ of wind generation installed in the UK at the end of December 2017 [23]. In Great Britain, wind and solar also have an impact on decarbonization and displacement of gas and coal plants, although this is less impactful than in New Zealand in the range considered in this paper-possibly due to wind generation in New Zealand having a more consistent monthly capacity factor (Figure 9).

In both systems, wind and solar are found to have diminishing carbon abatement impact as the total install capacity of each generation type increases (Figure 6). This relates to the inherent variability of generation from both sources, for example $4 \mathrm{GW}$ of solar power may produce as little as $300 \mathrm{MW}$ at the midday peak on a national level when irradiance is low, yet sufficient to cause oversupply on other days. This means that there is always an apparent need for either DC3 (storage) or DC4 (backup) assets.

An important result from this work from system operation perspective is the regularity (or otherwise) at which the intermittent renewables are sufficient to cover demand. This changes the dispatch strategy and requirement for DC4 assets-generation stations which are designed to provide power in the absence of energy storage or renewables (Figure 11). The impact is most pronounced in New Zealand, (Figure 11) and in the 2.0 GW of wind and $2.0 \mathrm{GW}$ of solar scenario, where the continuous requirement for DC4 assets for energy balancing is found to be $<50 \mathrm{MW}$. Conversely, Britain is found to need a $50 \%$ increase of wind and solar before DC4 use is close to being discontinuous.

As investigated in Figure 10, utilization of reversible electrical energy storage can impact the decarbonization through shifting overgeneration to times of low wind/solar resource. In New Zealand, the results support conversion of existing hydro assets to pumped or larger storage reservoirs as a possible option if there is an explicit aim of $100 \%$ renewable energy generation. However, this should be contrasted with the costs of alternatives such as biomass and hydrogen storage and needs to account for impacts of dry hydrological years where lake levels run lower on average-as outlined in [35]. In Great Britain, storage has a low percentage impact on fossil fuel reduction and the lack of natural hydro resource means that achieving storage of this scale requires other methods such as utilization of batteries in electric vehicles or via interconnectors [11]. Further work should be adopted to quantify and compare different national energy storage/DC3 strategies.

A sensitivity analysis has been performed of different electricity demand scenarios in New Zealand (Figure 7). As expected, this shows that increased demand means additional low carbon generation is required. In the scenarios assessed, the additional DC4 generation requirement is found to be lowest when the demand is spread over $24 \mathrm{~h}$ rather than a daylight load only due to the availability of wind for overnight load in the model data. However, smarter demand profiles which more closely align demand to generation of intermittent electricity could be valuable. The results for New Zealand are particularly interesting in the context of the Interim Climate Change Committee report which investigated a $100 \%$ renewable approach by overbuilding wind and solar generation, energy storage and demand response [40]. The results of this paper support an increased investment in wind and solar but also quantify the reduced requirement and deployment of backup assets. This should be considered when investigating the economic and carbon benefits or otherwise of "backup" assets in work such as [41].

There remains a relatively high usage of DC4 style assets in Great Britain — the highest solar/wind case in Table 5 still has more than $15 \%$ fossil fuel usage so the model sits outside the asymptotic range. This suggests that the required wind/solar for DC4 reduction are at different volumes relative to demand in Great Britain to New Zealand. This is in part due to the fact that the capacity factor of wind generation in the data is more consistent through the year-see Figure 9 and [27] meaning that it abates DC4 use through more time steps of the year. It should also be noted that the ability to call on relatively large volumes low carbon hydro generation in New Zealand (Figure 3a) boosts the relative size of the DC2 class each hour of the year. As such, there remains very little need for DC4 assets in New Zealand 
relative to Great Britain. This suggests that Britain should focus investment on low carbon DC1 and DC2 assets (in addition to wind and solar) in order to reduce utilization of high carbon DC4 assets.

The model makes assumptions around the way in which plants are dispatched to represent high level constraints in energy balancing and generation assets. These can be modified through altering the dispatch strategy or adding new dispatch classes to assess factors such as different market designs, cost optimization and energy storage dispatch strategies. However, by using historical data to represent meteorological variables, plant availability and demand, the model ensures reasonable assessment of future energy balancing with wind and solar within the power system- and the concurrent impacts of and on energy storage and DC4 assets. This is relevant and possible due to the increased availability and quality of wind and solar generation data. Further work on the model would introduce pricing from different generation sources in order to assess impacts on wholesale prices, market design and policy. Additionally, interventions which alter the yield and capacity factors of wind and solar or may be assessed (e.g., bifacial modules or different turbine designs) by adding simulated outputs of these plants into the model in the relevant dispatch class. This may also include simulation which reflects wind/solar data at different locations or indeed projected outputs from other technology such as tidal generation. The model has also only considered one meteorological year and as such the duration of the model may be extended to cover a wider range of years. Sensitivity to electric heat may also be explored, however it is cautioned that will need to consider correlations between weather and heat demand which need to be carefully considered when adding an electric heat load to the model.

The generation data used in both case studies includes underlying demand plus (technical and non-technical) transmission and distribution losses. Losses may be affected positively or negatively by the location of generation and changing load flows. For simplicity and to avoid load flow analysis, the impacts of transmission loses are not included in the model as these are best considered when looking at the specific impacts of a particular project.

The model has not been used to assess impacts on system stability, however, this could be performed by looking at the different operating states in which the future grid would operate within the model. There are numerous mechanisms for abating system stability impacts such as using hydro generation in a hot standby/spinning reserve mode [42], introducing artificial inertia in wind generation [43] and/or using frequency keeping via battery energy storage [44]. For comparison in Britain, penetration of low carbon generation (wind and solar) rose to $55.3 \%$ of demand on 21-September 2018 (reported in the media and confirmed by analyzing data from [21] and [25]). Transpower, the New Zealand system operator, reported that the system could contain up to $4 \mathrm{GW}$ of solar without major issues using energy storage and potentially up to $10 \mathrm{GW}$ with the hydro resource for management [45].

The work may also be expanded through integration of a more comprehensive wind dataset such as that in national wind data sets [46] This is particularly important for a model for countries such as New Zealand where wind is not evenly distributed around the country as it is in Great Britain. As such, the Great Britain model more closely reflects future wind generation profiles as the wind data used in the alternative scenarios represent a wider geographical and technological spread.

\section{Conclusions and Future Work}

This work has shown that a relatively simple method can be used with publicly accessible data to assess different demand/generation scenarios on a country scale. For New Zealand and Britain, both wind and solar are found to aid supply/demand matching and can assist with future decarbonization of electricity. Firstly, they have an important role in decarbonization but one which changes with changing demand patterns. Secondly, in sufficient quantities they can shift dispatchable generation classes, which presently operate continuously, to infrequent operation, which may affect economic and technical feasibility of some assets. Finally, the work shows that modest growth in wind/solar in New Zealand can create a near $100 \%$ decarbonized electricity system which is robust to future load growth. 
Author Contributions: All authors contributed to the writing of the manuscript. Lead author of work focused on development of method, results and discussion, A.C.; New Zealand specific context for work including validation power system performance in NZ, K.S.; validation of methodology and assistance with respect to system stability considerations, A.W.; academic context and sense check of paper, C.G.; co-development of method, introduction and literature review, S.S. All authors have read and agreed to the published version of the manuscript.

Funding: No specific funding has been used for this article.

Conflicts of Interest: There are no conflicts of interest to declare.

\section{References}

1. IPCC. Summary for Policymakers. In Global Warming of $1.5^{\circ} \mathrm{C}$. An IPCC Special Report on the Impacts of Global Warming of $1.5^{\circ} \mathrm{C}$ above Pre-Industrial Levels and Related Global Greenhouse Gas Emission Pathways; World Meteorological Organization: Geneva, Switzerland, 2018.

2. BP. Statistical Review of World Energy, June. 2019. Available online: https://www.bp.com/en/global/ corporate/energy-economics/statistical-review-of-world-energy.html (accessed on 15 March 2020).

3. DECC. 2050 Energy Calculator. 2013. Available online: http://2050-calculator-tool.decc.gov.uk/\#/home (accessed on 15 March 2020).

4. Bulavskaya, T.; Reynès, F. Job creation and economic impact of renewable energy in the Netherlands. Renew. Energy 2018, 119, 528-538. [CrossRef]

5. Mentis, D.; Andersson, M.; Howells, M.; Rogner, H.; Siyal, S.; Broad, O.; Korkovelos, A.; Bazilian, M. The benefits of geospatial planning in energy access-A case study on Ethiopia. Appl. Geogr. 2016, 72, 1-13. [CrossRef]

6. Child, M.; Nordling, A.; Breyer, C. Scenarios for a sustainable energy system in the Åland Islands in 2030. Energy Convers. Manag. 2017, 137, 49-60. [CrossRef]

7. Child, M.; Haukkala, T.; Breyer, C. The Role of Solar Photovoltaics and Energy Storage Solutions in a $100 \%$ Renewable Energy System for Finland in 2050. Sustainability 2017, 9, 1358. [CrossRef]

8. Bussar, C.; Stöcker, P.; Cai, Z.; Moraes, L.; Alvarez, R.; Chen, H.; Breuer, C.; Moser, A.; Leuthold, M.; Sauer, D. Large-scale Integration of Renewable Energies and Impact on Storage Demand in a European Renewable Power System of 2050. Energy Procedia 2015, 73, 145-153. [CrossRef]

9. Boßmann, T.; Staffell, I. The shape of future electricity demand: Exploring load curves in 2050s Germany and Britain. Energy 2015, 90, 1317-1333. [CrossRef]

10. Wiese, F. Renpass: Renewable Energy Pathways Simulation System. 2015. Available online: http://www. reiner-lemoine-stiftung.de/pdf/dissertationen/Dissertation_Frauke_Wiese.pdf (accessed on 15 March 2020).

11. Edmunds, R.; Cockerill, T.; Foxon, T.; Ingham, D.; Pourkashanian, M. Technical benefits of energy storage and electricity interconnections in future British power systems. Energy 2014, 70, 577-587. [CrossRef]

12. Loulou, R.; Remme, U.; Kanudia, A.; Lehtila, A.; Goldstein, G. Documentation for the TIMES Model—PART I. Available online: http://iea-etsap.org/docs/TIMESDoc-Intro.pdf (accessed on 15 March 2020).

13. Burandt, T.; Xiong, B.; Löffler, K.; Oei, P.-Y. Decarbonizing China's energy system-Modeling the transformation of the electricity, transportation, heat, and industrial sectors. Appl. Energy 2019, 255, 113820. [CrossRef]

14. Maruf, M.N.I. Maruf Sector Coupling in the North Sea Region-A Review on the Energy System Modelling Perspective. Energies 2019, 12, 4298. [CrossRef]

15. Díaz, P.; Van Vliet, O.; Patt, A. Do We Need Gas as a Bridging Fuel? A Case Study of the Electricity System of Switzerland. Energies 2017, 10, 861.

16. DeCarolis, J.F.; Hunter, K.; Sreepathi, S. The case for repeatable analysis with energy economy optimization models. Energy Econ. 2012, 34, 1845-1853.

17. Mason, I.; Page, S.; Williamson, A. A 100\% renewable electricity generation system for New Zealand utilising hydro, wind, geothermal and biomass resources. Energy Policy 2010, 38, 3973-3984. [CrossRef]

18. Schlömer, S.; Bruckner, T.; Fulton, L.; Hertwich, E.; McKinnon, A.; Perczyk, D.; Roy, J.; Schaeffer, R.; Schlömer, S.; Sims, R.; et al. Annex III: Technology-specific cost and performance parameters. In Climate Change 2014: Mitigation of Climate Change; Contribution of Working Group III to the Fifth Assessment Report of the Intergovernmental Panel on Climate Change; Cambridge University Press: Cambridge, UK, 2014.

19. Sovacool, B.K. Valuing the greenhouse gas emissions from nuclear power: A critical survey. Energy Policy 2008, 36, 2950-2963. [CrossRef] 
20. Krey, V.; Masera, O.; Blanford, G.; Bruckner, T.; Cooke, R.; Fisher-Vanden, K.; Haberl, H.; Hertwich, E.; Kriegler, D.; Mueller, S.; et al. Annex II: Metrics \& Methodology. In Climate Change 2014: Mitigation of Climate Change Contribution of Working Group III to the Fifth Assessment Report of the Intergovernmental Panel on Climate Change; Cambridge University Press: Cambridge, UK, 2014.

21. ELEXON. Balancing Market. Reporting Service. 2020. Available online: https://www.bmreports.com/bmrs/ (accessed on 21 March 2020).

22. Department for Business, Energy and Industrial Strategy Implementing the End of Unabated Coal by 2025; Department for Business, Energy and Industrial Strategy: London, UK. 2018. Available online: https://assets.publishing.service.gov.uk/government/uploads/system/uploads/attachment_data/file/ 672137/Government_Response_to_unabated_coal_consultation_and_statement_of_policy.pdf (accessed on 26 May 2020).

23. Department of Business. Energy and Industrial Strategy. Energy Trends Section 6: UK Renewables. 2020. Available online: https://www.gov.uk/government/statistics/energy-trends-section-6-renewables (accessed on 22 March 2020).

24. BMRS. Balancing Mechanism Reporting Service (BMRS). 2018. Available online: http://www.bmreports.com/ (accessed on 14 September 2018).

25. Sheffield University. Sheffield Solar. 2020. Available online: https://www.solar.sheffield.ac.uk/pvlive/ (accessed on 21 March 2020).

26. National Statistics. DUKES Chapter 6: Renewable Sources of Energy; Department for Business; Energy and Industrial Strategy: London, UK. 2019. Available online: https://www.gov.uk/government/statistics/ renewable-sources-of-energy-chapter-6-digest-of-united-kingdom-energy-statistics-dukes (accessed on 26 May 2020).

27. Ministry of Business, Innovation and Employment. Electricity Statistics. 2019. Available online: https://www.mbie.govt.nz/building-and-energy/energy-and-natural-resources/energy-statistics-andmodelling/energy-statistics/electricity-statistics/ (accessed on 1 November 2019).

28. Electricity Authority. Electricity Market Information. 2019. Available online: https://www.emi.ea.govt.nz/ (accessed on 1 November 2019).

29. Electricity Authority. Historical Electricity Risk Curves. 2019. Available online: https://www.emi.ea.govt.nz/ Environment/Reports/3UN1KD (accessed on 1 November 2019).

30. Connell Wagner. Transmission to Enable Renewables Economic Wind Resource Study Electricity Commission; Electricity Authority: Wellington, New Zealand, 2008.

31. New Zealand Wind Energy Association. Wind Turbine Technology; New Zealand Wind Energy Associatin: Wellington, New Zealand, 2020; Available online: http://www.windenergy.org.nz/store/doc/Wind_Turbine_ Technology.pdf (accessed on 26 May 2020).

32. PVSyst. Home. 2018. Available online: http://www.pvsyst.com/en/ (accessed on 17 September 2018).

33. Solar GIS. Solar Resource Maps of New Zealand. 2020. Available online: https://solargis.com/maps-and-gisdata/download/new-zealand (accessed on 26 March 2020).

34. Electricity Authority. Electricity Authority: Wholesale Datasets: Generation Output by Plant. 2018. Available online: https://www.emi.ea.govt.nz/Wholesale/Datasets/Generation/Generation_MD (accessed on 14 September 2018).

35. Transpower. Lower South Island Dry Summer System Security Report, Wellington. 2018. Available online: https:/www.transpower.co.nz/sites/default/files/bulk-upload/documents/Lower\%20South\%20Island\% 20Dry\%20Summer\%20Report.pdf (accessed on 26 May 2020).

36. Transpower. Te Mauri Hiko: Energy Futures, Wellington. 2018. Available online: https://www.transpower. co.nz/resources/te-mauri-hiko-energy-futures (accessed on 26 May 2020).

37. National Grid. Future Energy Scenarios, London. 2019. Available online: http://fes.nationalgrid.com/media/ 1409/fes-2019.pdf (accessed on 26 May 2020).

38. BusinessNZ Energy Council. New Zealand Energy Scenarios; BusinessNZ: Wellington, New Zealand, 2015.

39. Transpower. Hydro Information. 2019. Available online: https://www.transpower.co.nz/system-operator/ security-supply/hydro-information (accessed on 1 November 2019).

40. Interim Committee on Climate Change. Accelerated Electrification; Interim Climate Change Committee: Wellington, New Zealand, 2019. 
41. John Culy Consulting. ICCC Modelling: Comparative analysis of dry year backup options. 2019. Available online: https://www.iccc.mfe.govt.nz/assets/PDF_Library/fe507ec27d/Final-ICCC-modelling-dryyear-storage-options-analysis.pdf (accessed on 26 May 2020).

42. He, Z.; Zhou, J.; Sun, N.; Jia, B.; Qin, H. Integrated scheduling of hydro, thermal and wind power with spinning reserve. Energy Procedia 2019, 158, 6302-6308. [CrossRef]

43. Fernández-Guillamón, A.; Gómez-Lázaro, E.; Muljadi, E.; Molina-García, Á. Power systems with high renewable energy sources: A review of inertia and frequency control strategies over time. Renew. Sustain. Energy Rev. 2019, 115, 109369.

44. Engels, J.; Claessens, B.; Deconinck, G. Techno-economic analysis and optimal control of battery storage for frequency control services, applied to the German market. Appl. Energy 2019, 242, 1036-1049. [CrossRef]

45. Transpower. The Sun Rises on a Solar Energy Future; Transpower: Wellington, New Zealand, 2019; Available online: https://www.transpower.co.nz/about-us/transmission-tomorrow/sun-rises-solar-energyfuture (accessed on 26 May 2020).

46. NIWA. The National Climate Database. 2020. Available online: https://liflo.niwa.co.nz/ (accessed on 21 March 2020).

(C) 2020 by the authors. Licensee MDPI, Basel, Switzerland. This article is an open access article distributed under the terms and conditions of the Creative Commons Attribution (CC BY) license (http://creativecommons.org/licenses/by/4.0/). 